\title{
Home Automation dengan Memanfaatkan Mini Komputer Raspberry Pi sebagai Pengontrol Perangkat Elektronik melalui Jaringan Lokal
}

\author{
Home Automation Using Mini Computer Raspberry Pi as a \\ Control of Electronic Device through Local Network
}

\author{
Aprinal Adila Asril, Yul Antonisfia, Ihsan Lumasa Rimra \& Lifwarda
}

Jurusan Teknik Elektro Politeknik Negeri Padang Kampus Limau Manis Padang

Telp.0751-72590 Fax.0751-72576 Email: aprinal69@gmail.com

\begin{abstract}
Increased of human activity that can not be postponed in daily life make people do not have enough spare time to do a lot of activities at the same time. Here, the role of technology to simplify and facilitate the activities of humans in their daily life. By using the Raspberry Pi, was made a Home Automation system that can solve these problems. This system is also very useful to help people who have bad habits in terms of electric power saving and term life of an electronic device, as example is a simple habit when forgetting to turn off the television.

In this research a system designed make the user will be able to take control of some the electronic devices on the miniature house. Control is done by access to the webserver on Raspberry Pi, then take control over the local network. The local network consists of three networks that are connected by two Cisco Linksys WRT120N wireless router. When doing control, the Raspberry Pi connected to the relay module as a breaker and junction of electric current circuit of electronic devices.

Home automation test results show that to be able to access the electronic devices that are on the miniature home, the user and server must be connected in a local network. This system is accessible by cable and wireless media by passed some wireless router, this system will be implemented on the Internet.
\end{abstract}

Keywords : Home Automation, Raspberry Pi, wireless routers, Cisco Linksys WRT120N, Relay module, webserver.

\section{PENDAHULUAN}

Meningkatnya kesibukan manusia yang tidak dapat ditunda dalam kehidupan sehari-hari mengakibatkan manusia sekarang tidak memiliki cukup waktu luang untuk melakukan banyak kegiatan dalam waktu yang sama. Keterbatasan waktu dan jarak membuat manusia harus memilih salah satu aktivitas, sehingga aktivitas yang lain tidak dapat dikerjakan. Disinilah peran teknologi untuk mempermudah dan memperlancar kegiatan manusia dalam kehidupan sehari-hari.

Perkembangan ilmu pengetahuan terutama di bidang teknologi informasi dan telekomunikasi semakin meningkat dan berkembang dengan sangat cepat, sehingga menyebabkan suatu perangkat keras maupun perangkat lunak dapat dengan mudah dapat digunakan oleh seseorang maupun sekelompok orang. Ini ditandai dengan bermunculannya alat-alat yang menggunakan sistem digital dan otomatis. Salah satu contoh alat yang dapat digunakan adalah Raspberry Pi. Raspberry Pi adalah modul mikro komputer yang juga mempunyai input output digital port seperti pada board microcontroller yang dapat digunakan untuk mengontrol komponen elektronika.

Kelebihan dari raspberry pi ini yaitu memiliki ukuran fisik yang kecil, harga yang relative murah, dan untuk mengoperasikannya hanya memerlukan daya yang kecil seperti baterai. Selain itu mini komputer raspberry pi ini dilengkapi dengan port ethernet dan wifi dongle eksternal yang nantinya dapat terhubung ke jaringan lokal maupun internet. Contohnya apabila akan mengukur kedalaman laut, disini kita akan memerlukan 1 buah 
komputer yang difungsikan untuk mengirimkan data ke user yang berada didarat, hal ini akan menimbulkan kesulitan ketika membawa komputer tersebut ketengah laut. Untuk mengatasi hal tersebut digunakanlah raspberry pi ini.

\section{METODOLOGI}

\section{Konsep Perancangan Sistem Home Automation.}

Pada tahapan perancangan ini akan dibahas secara garis besar mengenai perangkat keras (Hardware) dan perangkat lunak (Software) yang digunakan dalam sistem. Sistem yang dibuat adalah home automation dengan pemanfaatan mini komputer Raspberry Pi sebagai pengontrolan perangkat elektronik melalui jaringan lokal.

Untuk membangun sistem home automation yang dapat diakses dari halaman web diperlukan adanya webserver. Webserver berguna untuk menerima request dan memberikan respond yang diterima melalui protocol HTTP yang terdapat pada layer aplikasi. Raspberry Pi sebagai pusat pengontrolan home automation bekerja dengan sistem operasi Linux Raspbian, sistem operasi ini cocok dengan Webiopi sebagai software aplikasi untuk webserver Raspberry Pi. Webiopi adalah sebuah software webserver opensource khusus Raspberry $P i$ yang dikembangkan oleh Eric Ptak.

Dalam sistem ini dibangun jaringan lokal, jaringan tersebut dibangun dengan menggunakan 2 wireless router Linksys Cisco WRT120N. Dimana, dengan 2 wireless router tersebut dapat dibuat replika jaringan Internet. Jaringan pertama akan menghubungkan komputer dengan wireless router 1, jaringan 2 akan menghubungkan wireless router 1 dengan wireless router 2 , dan jaringan 3 akan menghubungkan wireless router 2 dan Raspberry Pi.

Pengontrolan perangkat elektronik untuk home automation dapat menggunakan relay, sensor dan komponen lainnya. Namun, dalam pembuatan tugas akhir ini hanya menggunakan relay sebagai pengontrol home automation. Relay berfungsi sebagai pemutus dan penyambung arus Alternative Current (AC) yang tersambung pada perangkat elektronik. Komponen tersebut nantinya akan dikontrol melalui jaringan lokal dengan Raspberry P $i$ sebagai server.

\section{Blok Diagram Home Automation.}

Home automation yaitu sistem rumah otomatis yang dapat memudahkan pengguna untuk mengontrol perangkat rumah dimana saja. Untuk dapat mengakses perangkat elektronik yang terdapat dalam rumah, user harus terhubung dalam jaringan lokal. Kemudian user melakukan kontrol terhadap Raspberry Pi yang berfungsi sebagai pusat kontrol dan server, untuk melakukan otomatisasi terhadap perangkat rumah yang terhubung dengan relay seperti yang digambarkan pada gambar 1 blok diagram sistem home automation.

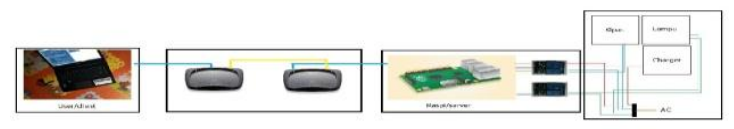

Gambar 1. Blok Diagram Sistem Home Automation

\subsection{Flow Chart Home Automation.}

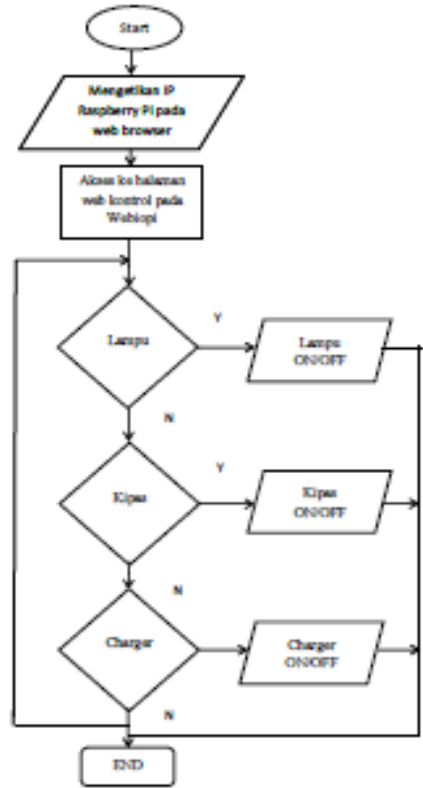

Gambar 2. Flowchart Sistem Home Automation 
Gambar 2 memperlihatkan diagram alir dari sistem home automation, dimana user terlebih dahulu melakukan akses ke server dengan mengetikan IP Raspberry $R i$ sehingga dapat melakukan akses terhadap halaman Webiopi. Kemudian dengan menekan nama perangkat, maka server akan melakukan proses automasi terhadap perangkat yang berada di rumah. Dari halaman web yang diakses, terdapat 3 tombol yang akan melakukan kontrol terhadap perangkat elektronik.

\section{Alat serta Bahan dalam Perancangan dan Pembuatan.}

Berikut alat dan bahan yang digunakan untuk pengkontrol perangkat elektronik antara lain.
a. Raspberry Pi Model B+
b. Modul Relay
c. Kabel Jumper
d. Kabel UTP
e. Linksys Cisco WRT120N
f. Terminal AC

\section{Raspberry Pi Model B+}

Raspberry $P i$ adalah sebuah mini komputer yang bekerja dalam sistem operasi Linux, contoh: Raspbian, OpenElec, NOOBS dan masih banyak lagi. Raspberry $P i$ Model $\mathrm{B}+$ dilengkapi dengan BCM2835, RAM sebesar $512 \mathrm{Mb}$, dan 40 buah GPIO, serta sebuah Ethernet Port untuk terhubung dalam jaringan LAN seperti yang terlihat pada gambar 3 .

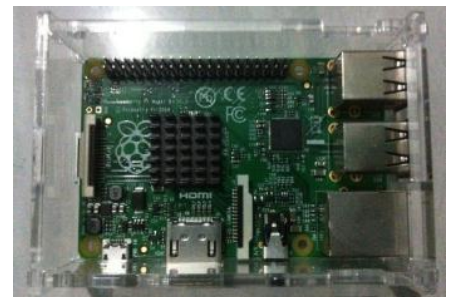

Gambar 3. Mini Komputer Raspberry Pi Model B+

\section{Modul Relay}

Relay adalah komponen elektronika berupa saklar yang dikendalikan oleh arus listrik. Relay bekerja dengan menggunakan gaya elektromagnetik untuk menutup dan membuka saklar kontak. Gambar 4 adalah gambar relay yang memiliki tegangan input dan output 10VDC/220VAC.

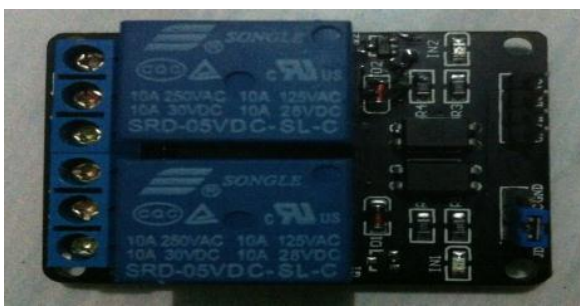

Gambar 4. Modul Relay SDR-05VDC-SL-C

\section{Kabel Jumper}

Kabel jumper berfungsi untuk menghubungkan pin-pin yang akan digunakan pada setiap modul. Pada gambar 5 dibawah ini merupakan kabel-kabel jumper.

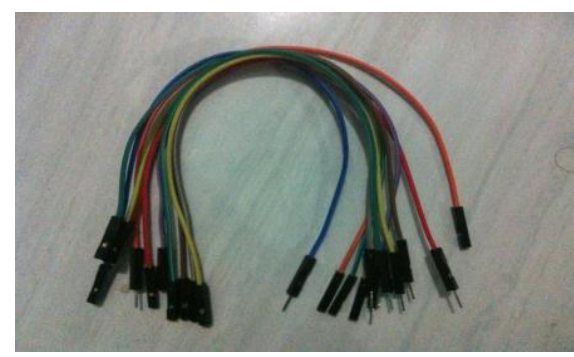

Gambar 5. Kabel Jumper

\section{Kabel UTP}

Kabel pilin (UTP wired), yang sering dikenal Unshielded Twisted Pair. Gambar 6 adalah gambar kabel UTP yang biasa digunakan untuk melakukan transmisi melalui jaringan komputer.

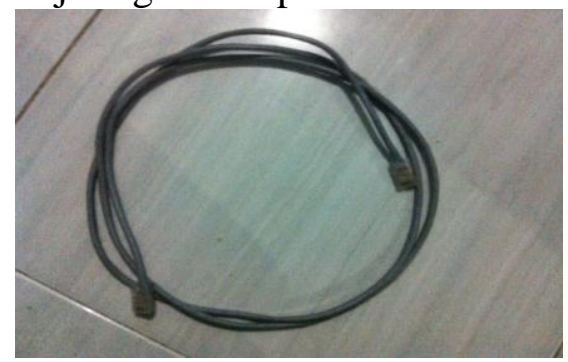

Gambar 6. Kabel UTP

\section{Linksys Cisco WRT120N}

Linksys cisco WRT120N yaitu salah satu produsen yang memberikan perangkat wireless dengan kualitas yang baik dengan desain yang menarik serta semua fitur yang ada dalam varian produknya digunakan untuk meningkatkan kecepatan koneksi 
internet dalam kondisi cuaca apapun. Berikut gambar 7 adalah wireless router dengan produsen Cisco.

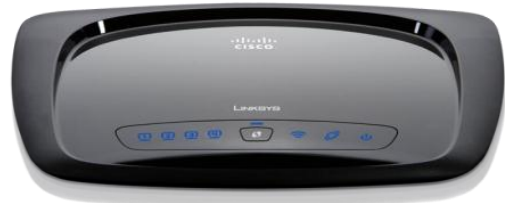

Gambar 7. Cisco WRT120N

\section{Terminal Alternative Current $(\mathrm{AC})$}

Terminal AC digunakan untuk membagi arus AC yang mengalir pada setiap lubang terminal dengan menggunakan kabel. Gambar 8 adalah gambar fisik terminal AC.

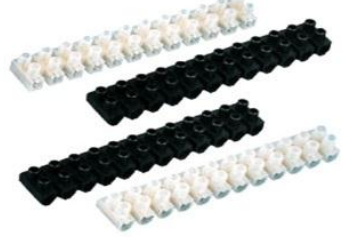

Gambar 8. Terminal AC

\section{Pembuatan Sistem Home Automation}

Pembuatan sistem home automation dengan melalui jaringan lokal dapat dimulai dengan pembangunan replika jaringan Internet dengan WRT120N, kemudian membuat sebuah replika rumah dan memasang modul relay yang tersambung pada Raspberry $P i$ sebagai pengontrol perangkat elektronik untuk home automation.

\section{Membangun 3 Jaringan Lokal dengan WRT120N}

Untuk membangun sebuah jaringan lokal untuk implementasi Internet perlu adanya beberapa jaringan yang saling berhubungan satu sama lain. Pada projek ini dibangun 3 buah jaringan seperti gambar 9 , dimana jaringan 1 terhubung antara komputer user dengan wireless router 1 yang memiliki IP 192.168.1.X. Jaringan 2 menghubungkan antara wireless router 1 dan wireless router 2 dengan IP 192.168.2.X. Sedangkan jaringan 3 menghubungkan antara wireless router 2 dan Raspberry Pi dengan IP 192.168.3.X. Ketiga jaringan tersebut dikonfigurasi agar dapat terhubung satu sama lain dan akan membuat replika dari jaringan Internet.

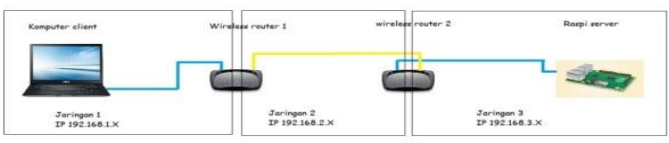

Gambar 9. Blok Jaringan Lokal dengan 2 Wireless Router.

Raspberry $P i$ tipe $\mathrm{B}+$ memiliki 2 interface untuk terhubung pada jaringan, untuk tersambung pada jaringan maka butuh konfigurasi pada interface. Berikut langkah-langkah mengkonfigurasi Raspberry $P i$ agar tersambung pada jaringan.

1. Melakukan kontrol pada Raspberry $P i$ melalui Putty, masukan IP 192.168.137.1 kemudian pilih Open.

2. Login dengan pi, kemudian masukkan password Raspberry Pi. maka remote dapat dilakukan dengan akses Secure Shell (SSH).

3. Untuk melakukan konfigurasi pada interface Raspberry Pi, ketikan sudo nano /etc/network/interfaces.

4. Masuk kedalam script konfigurasi seperti yang terlihat pada gambar 31, ubah iface etho inet manual menjadi iface ethO inet dhcp seperti yang terdapat pada kotak biru. Code ini nantinya akan membuat IP Ethernet Raspberry Pi secara otomatis diberikan oleh wireless router.

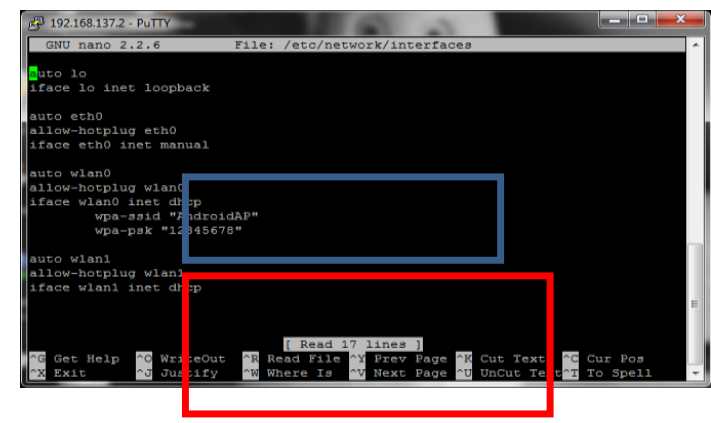

Gambar 10. Konfigurasi interface Raspberry Pi 
Untuk menyambungkan wireless local area network (WLAN) Raspberry Pi ke wireless router 2, masukan perintah seperti yang terlihat pada kotak merah pada gambar 10. Wpa-ssid adalah nama service set identifier (SSID) yang ingin disambungkan, kemudian wpa-psk adalah password dari SSID yang ingin disambungkan.

5. Keluar dari konfigurasi, lalu restart Raspberry $P i$ dengan mengetikan sudo reboot.

\section{Pemasangan Modul Relay untuk Home Automation}

Raspberry Pi model B+ memiliki 40 pin header GPIO yang memiliki bermacammacam fungsi. GPIO pada Raspberry Pi juga memiliki 2 penamaan, penamaan berdasarkan urutan pin dan penamaan berdasarkan Broadcom Corporation System on Chip (BCM SoC). Pemasangan pin GPIO pada relay dapat dilahat pada tabel 1.

Tabel 1. Pemasangan Pin GPIO pada Relay

\begin{tabular}{ccccc}
\hline No & Pin & $\begin{array}{c}\text { Nama } \\
\text { BCM }\end{array}$ & $\begin{array}{c}\text { Modul } \\
\text { Relay 1 }\end{array}$ & $\begin{array}{c}\text { Modul } \\
\text { Relay 2 }\end{array}$ \\
\hline 1 & 2 & $5 \mathrm{v}$ & Vcc & - \\
\hline 2 & 4 & $5 \mathrm{v}$ & - & Vcc \\
\hline 3 & 6 & Ground & Ground & - \\
\hline 4 & 9 & Ground & - & Ground \\
\hline 5 & 11 & GPIO17 & IN1 & - \\
\hline 6 & 13 & GPIO25 & IN2 & - \\
\hline 7 & 22 & GPIO27 & - & IN1 \\
\hline
\end{tabular}

Dari tabel 1, pin 2 dan 4 pada Raspberry Pi digunakan untuk memberikan arus DC pada relay, sehingga relay akan aktif. Pin 4 dan 6 berfungsi sebagai ground, dan pin 11, 13, 22 berfungsi sebagai input output untuk mematikan kedua relay. Masing-masing pin tersambung dengan relay menggunakan kabel jumper.
Akses Home Automation menggunakan Smartphone

Berikut adalah langkah-langkah untuk melakukan kontrol Home Automation dengan menggunakan Smartphone.

1. Hidupkan wi-fi smartphone, sehingga wi-fi pada smartphone secara otomatis melakukan pencarian perangkat wi-fi yang tersedia.

2. Pilih SSID yang sesuai dengan wireless router 1, yaitu Linksys.

3. Masukkan password SSID Linksys, yaitu 12345678.

4. Tunggu hingga smartphone mendapatkan IP dari wireless router 1 atau indikator wi-fi connected pada smartphone aktif.

5. Buka web browser, kemudian masukkan IP server pada URL.

6. Jika tidak terjadi masalah pada koneksi, maka halaman web kontrol perangkat home automation akan tampil.

\section{HASIL DAN PEMBAHASAN}

\section{Hasil Pengujian}

Hasil pengujian untuk home automation yang telah dibuat dilakukan ke beberapa perangkat elektronik yang telah terpasang pada miniature rumah.

\section{Tujuan Pengujian}

Tujuan dari pengujian yaitu untuk melakukan pengontrolan perangkat elektronik yang telah terpasang pada miniature rumah (home automation) melalui jaringan lokal. Kemudian melakukan analisa terhadap lalu lintas data antara client (komputer) dan server (Raspberry Pi).

Perangkat yang akan Diuji.

Tabel 2. Daftar perangkat yang akan diuji

\begin{tabular}{cll}
\hline No & Perangkat & \multicolumn{1}{c}{ Spesifikasi } \\
\hline 1 & $\begin{array}{l}\text { Lampu } \\
\text { Pijar }\end{array}$ & Phillips 220-240 VAC, 15 Watt \\
\hline 2 & $\begin{array}{l}\text { Kipas } \\
\text { (cooling- } \\
\text { pad) }\end{array}$ & $\begin{array}{l}\text { Cooling-pad 5 VDC, adapter output 5 } \\
\text { VDC dan input 100-200 VAC }\end{array}$ \\
\hline 3 & Charger Hp & $\begin{array}{l}\text { Charger samsung output 5 VDC dan } \\
\text { input 100-200 VAC }\end{array}$ \\
\hline
\end{tabular}




\section{Proses Pengujian}

Proses pengujian diawali dengan melakukan pengujian koneksi perangkat terhadap jaringan lokal, pengujian perangkat elektronik untuk home automation.

\section{Pengujian Koneksi Perangkat}

Berikut merupakan langkah-langkah pengujian koneksi perangkat dengan jaringan lokal.

1. Sambungkan komputer (client) dengan wireless router 1 , kemudian tes koneksi antara komputer dan wireless router 1 dengan mengetikkan "ping 192.168.1.1" pada command promt. Jika berhasil maka akan tampil seperti gambar 11 .

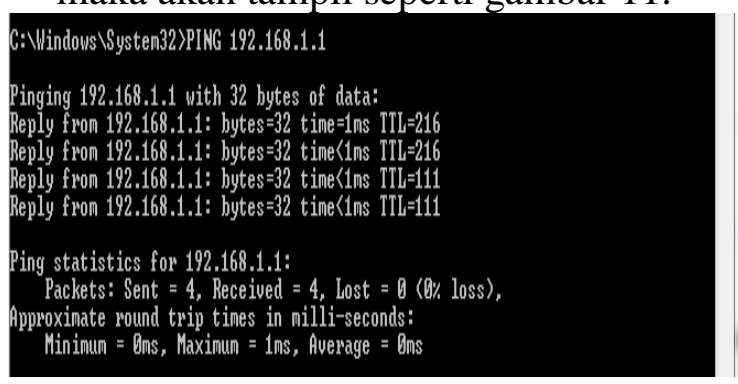

Gambar 11. Pengujian koneksi antara komputer dan wireless router 1

2. Selanjutnya uji koneksi antara komputer dan wireless router 2, dengan mengetikkan "ping 192.168.3.1". Jika berhasil maka akan tampil seperti gambar 12.

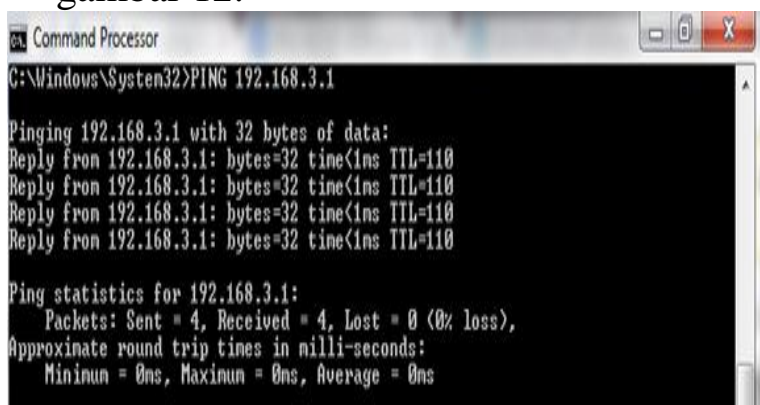

Gambar 12. Pengujian koneksi antara komputer dan wireless router 2

3. Terakhir uji koneksi antara komputer (client) dan Raspberry Pi (server), dengan mengetikkan "ping 192.168.3.102". Jika berhasil maka akan tampil seperti gambar 13.

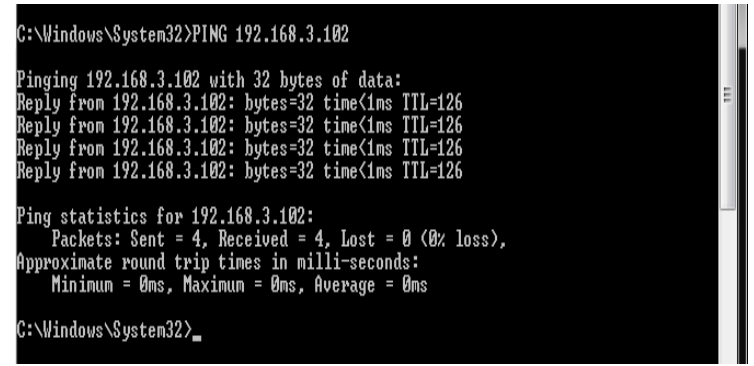

Gambar 13. Pengujian koneksi antara komputer dan Raspberry $P$

\section{Hasil Pengujian Home Automation}

Setelah melakukan pengujian koneksi, kemudian melakukan pengujian dari sistem home automation. Halaman Webiopi dapat diakses dengan mengetikkan IP Raspberry Pi yaitu 192.168.3.102, maka akan tampil halaman web dari home automation seperti gambar 14 berikut.

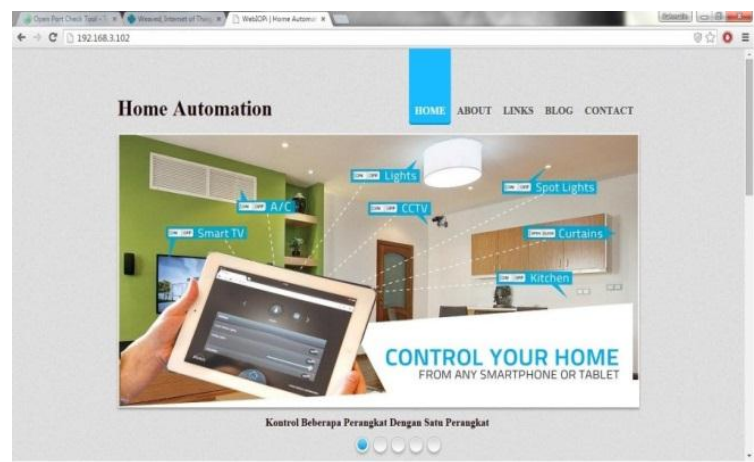

Gambar 14. Tampilan Halaman Web Home Automation

Dengan menekan tombol yang terdapat pada halaman web, maka perangkat yang terdapat pada miniature rumah akan hidup atau mati. Ketika tombol lampu ditekan, maka tombol lampu pada web akan berwarna merah. Indikator warna merah menandakan bahwa keadaan lampu pada miniature rumah yaitu nyala, atau Raspberry $P i$ memberikan input relay 0 sehingga relay memberikan jembatan terhadap arus AC menuju lampu.

Tabel 3. Hasil Pengujian Home Automation melalui Webiopi

\begin{tabular}{cccccc}
\hline No & Button & $\begin{array}{c}\text { Indikat } \\
\text { or } \\
\text { warna }\end{array}$ & $\begin{array}{c}\text { Keadaan } \\
\text { Perangkat }\end{array}$ & $\begin{array}{c}\text { Indikator } \\
\text { warna } \\
\text { button } \\
\text { pada web }\end{array}$ & $\begin{array}{c}\text { Keadaan } \\
\text { Perangkat }\end{array}$ \\
\hline 1 & Lampu & Merah & Nyala & Hitam & Mati \\
\hline 2 & Kipas & Merah & Nyala & Hitam & Mati \\
\hline 3 & Charger & Merah & Nyala & Hitam & Mati \\
\hline
\end{tabular}


Tabel 3 diatas adalah hasil lengkap dari pengujian home automation dengan pemanfaatan Raspberry $P i$ sebagai pengkontrol perangkat elektronik. Dimana ketika indikator warna button pada web berwarna merah maka keadaan perangkat adalah nyala, sedangkan ketika indikator warna button pada web berwarna hitam maka keadaan perangkat adalah mati. Gambar 15 adalah salah satu hasil pengujian perangkat yang terdapat dalam miniature rumah. User menghidupkan lampu tersebut dengan menggunakan web yang telah dibuat melalui jaringan lokal.

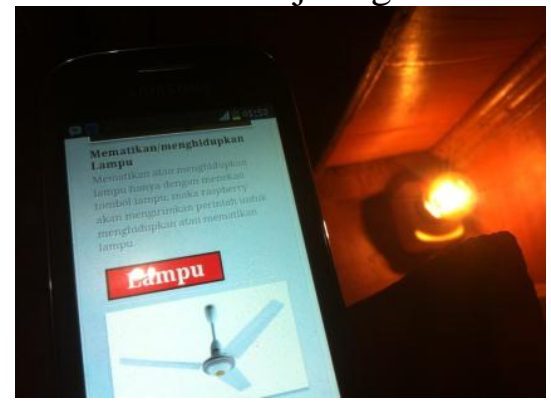

Gambar 15. Salah satu hasil pengujian untuk menghidupkan perangkat.

\section{Pembahasan Data melalui Wireshark}

Untuk mengetahui perintah kontrol atau data yang terkirim dari user ke Raspberry $\quad P i$ maka digunakanlah Wireshark sebagai aplikasi tool analisa jaringan. Berikut analisa yang didapat dari Wireshark.

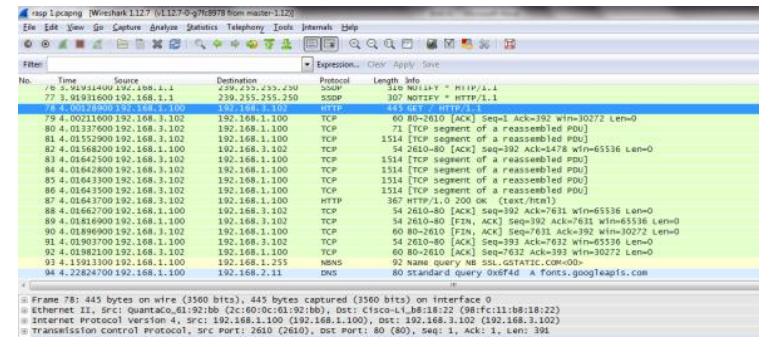

Gambar 16. Proses Permintaan data HTTP

Frame 78 pada gambar 16, memperlihatkan bahwa client dengan IP 192.168.1.100 meminta HTTP ke server yang memiliki IP 192.168.3.102. Selanjutnya pada frame 79 , server memberitahukan bahwa server telah mengirimkan data informasi yang direassembled pada frame 80 dan 81 . Pemberitahuan pengiriman paket dari server ke client ditandai oleh $[\mathrm{ACK}]$ atau acknowledge. Client dan server akan terus melakukan request dan respon data hingga halaman web tampil sempurna, atau pemberitahuan dari server yang ditandai dengan [FIN, ACK] yang berarti pemberitahuan transmisi paket selesai.

Saat menekan tombol lampu, client mengirim frame 1716 ke server. Frame ini berisikan data dari protocol HTTP, TCP, IP, data link. Pada protocol HTTP berisikan informasi sebesar 415 bytes yang terdiri dari POST, Request Method hingga \rv seperti yang terlihat pada kotak merah pada gambar 17.

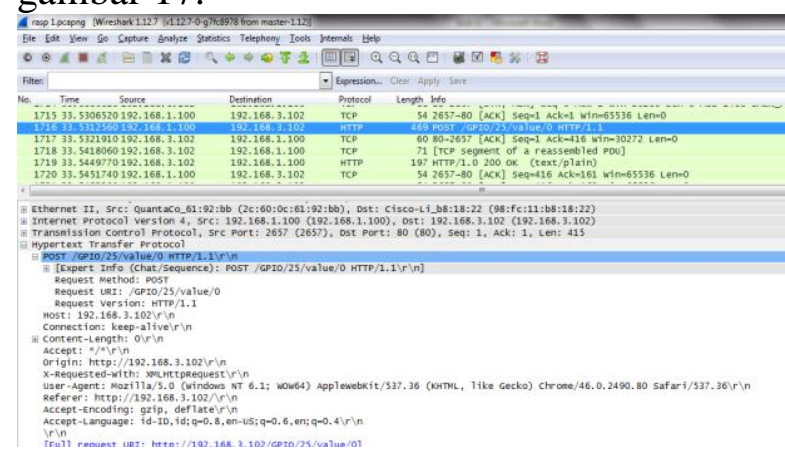

Gambar 17. Protocol HTTP

Pada kotak merah, informasi POST /GPIO/25/value/0 memiliki arti bahwa client ingin menjadikan GPIO 25 bernilai 0 . Nilai 0 pada GPIO akan membuat relay aktif dan memberikan arus listrik AC pada lampu. Selain itu pada protocol HTTP juga memberi tahukan bahwa host yang dituju oleh protocol ini adalah 192.168.3.102.

Protocol HTTP yang berisi data 415 bytes tersebut, kemudian dibungkus oleh protocol TCP yang memiliki data sebesar 20 bytes. Data pada protocol TCP berisikan informasi seperti Source port, Destination port, hingga Urgent point. Pada gambar 48 terlihat bahwa alamat port sumber adalah 2657, kemudian alamat port tujuan paket adalah 80 . Selanjutnya protocol TCP akan dibungkus oleh protocol IP yang memiliki data sebesar 20 bytes. Pada protocol IP terdapat informasi Source IP, Destination IP, Version, Time To Live dan lain-lain. Pada kotak hijau gambar 49 terlihat bahwa alamat IP sumber adalah 192.168.1.100, alamat IP tujuan 192.168.3.102, dan versi IP adalah IP versi 4. Keseluruhan data IP 
dibungkus lagi oleh protocol Ethernet atau data link, yang memiliki data sebesar 14 bytes. Protocol Ethernet berisi informasi MAC address sumber, MAC address tujuan, dan type. Pada gambar 50 terlihat bahwa, MAC address sumber adalah QuantaCo_61:92:bb(2c:60:0c:61:92:bb), untuk MAC address tujuan adalah Destination: Cisco-Li_b8:18:22 (98:fc:11:b8:18:22), dan types atau data yang ada didalam Ethernet adalah IP.

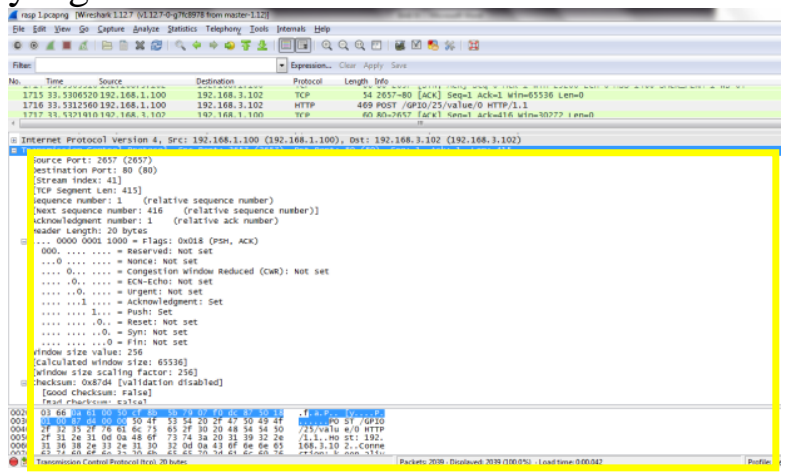

Gambar 18. Protocol TCP

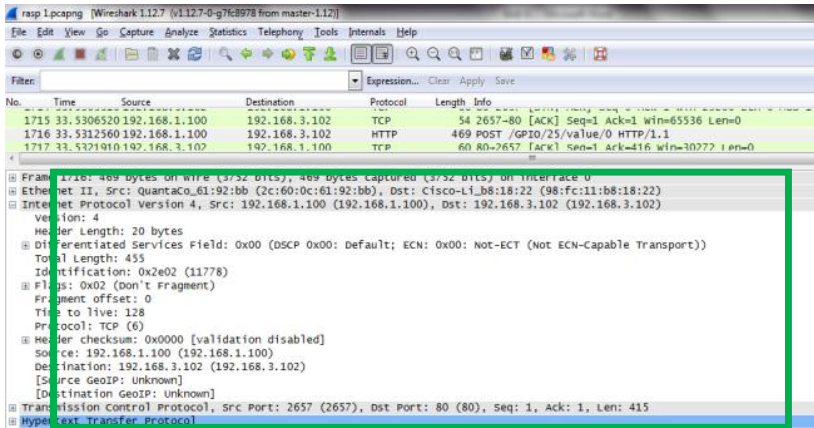

Gambar 19. Protocol IP

Sebelum pengiriman data, proses terakhir adalah encapsulation/pembungkusan protocol data link menjadi sebuah frame. Gambar 20 memperlihatkan frame 1716 dengan data informasi sebesar 469 bytes yang terdiri dari protocol HTTP, TCP, IP, dan data link. Frame akan dikirim sesuai informasi yang terdapat pada tiap-tiap protocol.

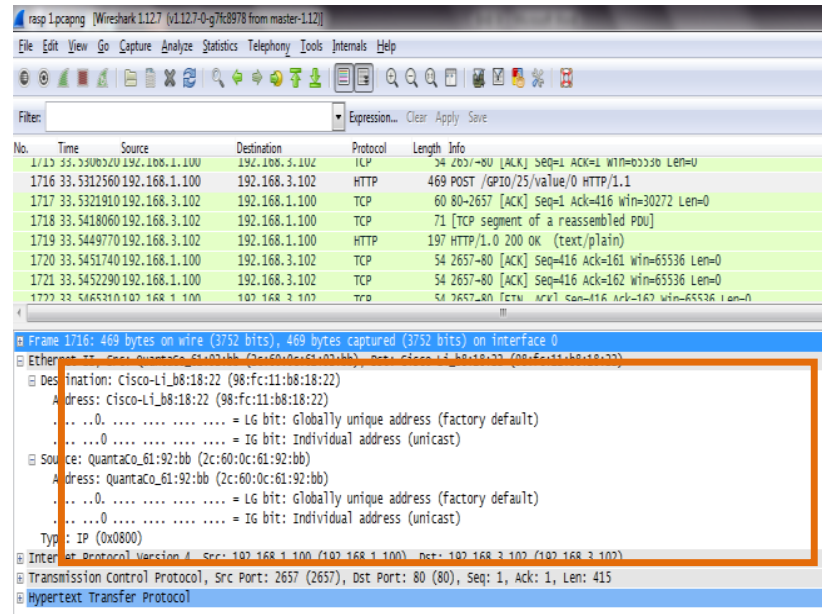

Gambar 20. Protocol Data link

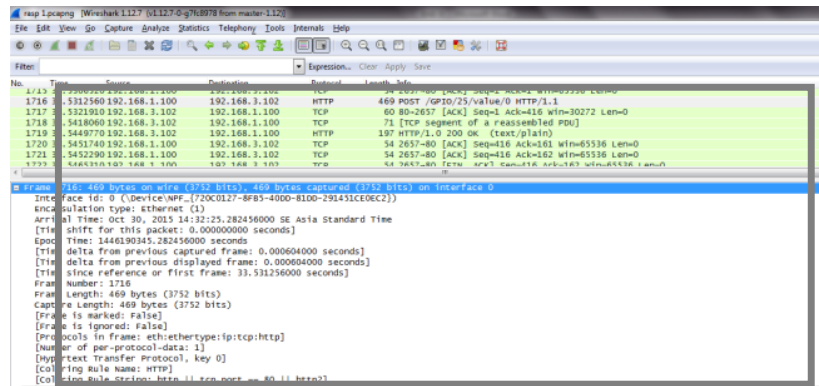

Gambar 21. Frame 1716

Ketika frame sampai pada sisi penerima, maka frame akan dibuka/decapsulation pada tiap-tiap layer. Jika data yang diterima sesuai alamat, maka penerima akan melakukan pembalasan/respond informasi yang ada pada paket. Dari isi protocol HTTP pengirim menginstruksikan agar GPIO 25 bernilai 0, maka penerima (Raspberry Pi) akan mengubah nilai GPIO menjadi 0 . Setelah itu server (Raspberry $\mathrm{Pi}$ ) akan mengirimkan balasan seperti frame 1766 yang terdapat pada gambar 21. Frame 1766 berisi informasi Java Object Notation yang dibungkus pada protocol HTTP. Java Object Notation memberitahukan kondisi objek seperti universal asynchronous receiver/transmitter (UART), serial peripheral interfaces (SPI), inter integrated circuit (I2C), ONEWIRE, dan GPIO. Pada gambar 21 diperlihatkan bahwa member key GPIO sub member key 25 memiliki number value 0 , yang berarti bahwa GPIO 25 dalam keadaan aktif. Sedangkan pada member key 22 , memiliki number value 1 yang berarti GPIO 22 dalam keadaan mati. 


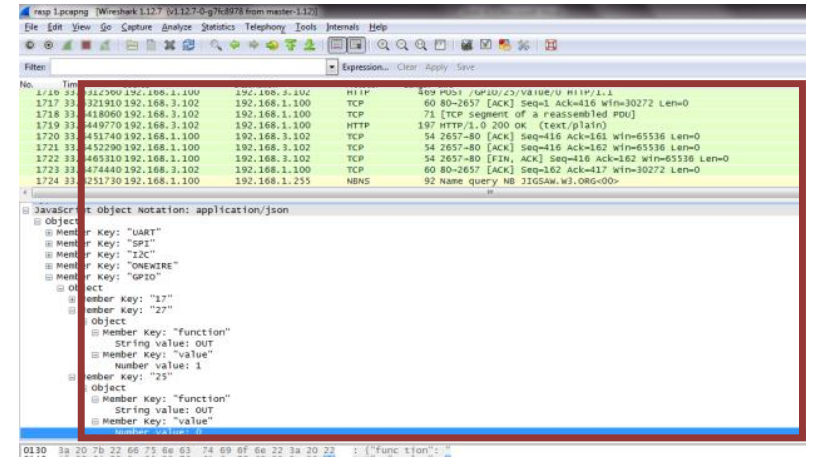

Gambar 22. Status GPIO pada Frame 1766

\section{SIMPULAN}

Berdasarkan pengujian dan analisa yang telah dilakukan, maka dapat disimpulkan sebagai berikut.

1. Untuk dapat mengakses perangkat elektronik yang berada pada miniature rumah maka user dan server harus terhubung dalam jaringan lokal.

2. Sistem ini dapat mengontrol perangkat elektronik secara wireless dan kabel.

3. Sistem ini nantinya dapat diimplementasikan pada internet.

4. Dengan menggunakan sistem ini, dapat melakukan pengontrolan dan penghematan daya.

\section{UCAPAN TERIMA KASIH}

Penulis mengucapkan terima kasih kepala laboratorium Telekomunikasi Multimedia yang telah mengizinkan untuk menggunakan beberapa perangkat sehingga system ini selesai sesuai dengan tujuan yang diinginkan.

\section{DAFTAR PUSTAKA}

[1] Casad Joe. 2012. Sams Teach Yourself TCP/IP in 24 Hours. Edition 5. Indianapolis: Sams Publishing.

[2] Dwita Nefitriani. 2014. "Pembuatan Jaringan Sensor Nirkabel (Wireless Sensor Network) Menggunakan Topologi Mesh (Komunikasi Router Dengan Coordinator Node)". Tugas Akhir. Padang: Jurusan Teknik Elektro PNP.

[3] Dwi Soemarwanto. 2008. Jaringan Komputer DanPemanfaatannya.
Online),(http://eprints.binadarma.ac. id/1469/1/INFRASTRUKTUR \%20INFORMASI\%20BISNIS\%20 MANAJEMEN\%20INFORMATIK A\%20MATERI\%201.pdf, diakses 20 September 2015).

[4] Eko Radiansyah, Muhamad suyatno,. Sunnarsih. 2014. Analisis dan Pemanfaatan Jaringan Wireless menggunakan LINKSYS SMART WIFI CISCO ROUTER E250, (Online),

(http://news.palcomtech.com/wpcontent/uploads/2014/10/ Jurnal_Eko_Yatno_Sun_AnalisisDa nPemanfaatanJaringanWirelessMen ggunakanLinksysSmartWifiCiscoR outerE2500.pdf, diakses 30 November 2015)

[5] Ignatius Devit. 2012. "Rancang Bangun Aplikasi Pemesanan Paket Pernikahan Berbasis Web (Studi Kasus Pada CV. Dewi Sri Malang)". Undergraduate thesis. Surabaya: Jurusan Sistem Informasi STIKOM.

[6] Matt Richardson and Shawn Wallace. 2012. Getting Started with Raspberry Pi. Edition 1. Sebastopol: O’Reilly Media, Inc.

[7] Maya Rahayu, Arjuni Budi P., Erik Haritman. 2014. Pengontrolan Alat Elektronika Melalui Media Wi-Fi Berbasis Raspberry Pi, (Online), http://jurnal.upi.edu/2897/view/289 7/pengontrolan-alat-elektronikamelalui-media-wi-fi-berbasisraspberry-pi.html, diakses 18 September 2015).

[8] Nanang Syahron., Ferry Astika Saputra. 2013. Dasar Jaringan Komputer, (Online), (http://ferryas.lecturer.pens.ac.id/20 12_2013/PendAK/ Jarkom-d4.pdf, diakses 24 September 2015).

[9] Suryadi Candra, Rusli Harianto., Denny Nugroho Kumara. 2010. "Analisis Dan Perancangan Sistem Jaringan Berbasis Vpn Dengan Metode Remote Access Pada Pt. Sandang 
Makmur Anugrah". Undergraduate thesis. Jakarta: Teknik Informatika BINUS.

[10] Tim Cox. 2014. Raspberry Pi Cookbook for Python Programmers. Edition 1. Birmingham: Packt Publishing Ltd.

[11] Umi Proboyekti . 2015. Jaringan Komputer, (Online), (http://lecturer. ukdw.ac.id/othie/Jaringan_Kompute r.pdf, diakses 20 September 2015).

[12] Yeffry Handoko Putra , Abdillah Ibnul Hakim., Malik. 2013. "Pemanfaatan Mini Pc Raspberry Pi Sebagai Pengontrol Jarak Jauh Berbasis Web Pada Rumah". Tugas Akhir. Bandung: Jurusan Teknik Komputer UNIKOM. 